Simon Hajdini"

\title{
Names at the Tip of the Nose'
}

\section{The Name of the Rose}

The problem of naming is not just any philosophical problem, but rather one that is central to classical ontology, the latter depending on the notion of names (onomata) as latching onto things (pragmata) in their essential being. As such, the name has traditionally been tied to the concept of truth as adequatio or correspondence between knowledge and being, intellect and thing, or proposition and reality. Accordingly, the problem of naming lies at the core of the issues of objectivity (truth) and fiction, as addressed in this issue of Filozofski vestnik. Probing and circumventing the double trap of "transcendentalism" and "new materialism," I propose to cast a side-glance at this massive philosophical problem, approaching it from the singular point of view of smells and their striking relationship to language.

"What's in a name?" Juliet asks, immediately putting us on the scent: "That which we call a rose / By any other word would smell as sweet." (Romeo and Juliet, II, ii, 1-2) It is no coincidence that Juliet expands on her initial question by relating names to the anomic realm of smells. In Indo-European languages at least, smells notoriously lack proper names, in turn acquiring roundabout names such as "smell of rose." Smells are eponymous: to name them is to relate them to their sources, to the names of objects that emit them, rather than naming the objects, or qualities, that they themselves are. Their essential being eludes signification such that we can only ever speak of them without speaking them out. Smells are metonymical: to name them is to speak of them as if they were unwanted guests at our dinner table whom we could only address in the third person, slandering them in their presence. Metonymically named, smells strike us as essentially euphemistic. But unlike euphemisms proper that-in providing

1 This article is the result of the research project J6-8263 "The Structure and Genealogy of Indifference" that was funded by the Slovenian Research Agency. 
indirect expressions substituted for those considered too disagreeable-make out the vast and ever-shifting socio-cultural lexicon of embarrassment, smells are reflectively euphemistic and therefore indicative of the embarrassment of language itself. In her adage, Juliet moves, in a single speculative stroke, from a name to a smell, that is: from naming to a void of naming.

Two typical instances of this metonymicity of smell, singular among the physical senses, are found in Juliet's passage. First, there's "a rose," "the smell of rose," uttering a smell's missing proper name as its descriptive source-name. Here, the smell-name is voiced with a reference to an object ("a rose") with which the particular subjective sensation of smell (the unnamed " $\mathrm{X}$ ") is correlated. And second, there's "sweetness," "the sweet smell," where the unnamed " $X$ " is named not in relation to its source, or objective correlate, but by being stepnamed, that is, by borrowing its name from the register of taste as the other of the two chemical senses. In the absence of first names, smells only have second names. However, they only acquire these nomina impropria either as orphans, structurally abandoned by their linguistic parents who are always-already dead and unknowable, or as sensuous bastards, as illegitimate children of a foreign household of sense. Every scent is the second scent. However, contrary to de Beauvoir's notion of the second sex as the Other in relation to the first sex, there is no first scent, no default expression that could be related to or substituted for another. Altogether lacking their proper place in the Other as the locus of speech, smells are always called "by any word other" than their own.

When step-named, smells typically borrow their names from the vocabulary of gustatory perception. However, one also speaks of smell "faces" and "palettes," relating smells to visual perception; of smells as "compositions" containing "notes" and "sub-tones," relating them to the sense of hearing; and one even relates smells to the sense of touch by calling them "pungent." Such synesthetic borrowing, as well as source-naming, are common among the senses ("sweet voice," "sharp taste," "warm color," etc.), however, with smells such source- and step-naming take place in curious absence of nomina propria that would be distinctive of them. Imagine a case of color anomia in which, when referring to the color "white," the subject would be obliged to use a source-name and say, for instance, "(the appearance of) snow," or a step-name such as "(it looks) cold." That is precisely what we do with smells each and every time we name them. 
What's in a smell? Pausing to consider synesthetic borrowing, Aristotle mentions the lack of generic names for smells while adding that "because smells are much less easy to discriminate than flavours, the names of these varieties are applied to smells in virtue of similarity" (De anim. 2.9). ${ }^{2}$ However, we should add, such an application of step-names to smells "in virtue of similarity" is underpinned, and necessitated, by a blatant "similarity disorder," to deploy Roman Jakobson's famous term. Smells stand for lexical voids and represent the singular site of a universal linguistic disturbance, a universal olfactory anomia. That is to say, we are capable, for the most part, of naming smells in a roundabout metonymical way, typically relating them to the names of their sources, but are materially barred from directly metaphorically grasping them, such that the signifying function of, say, "smell of" ... "rose" is congruent with the elision of meaning. ${ }^{4}$

Jakobson illustrates the similarity disorder as it effects the elision of meaning, and as relating to the impossibility of metaphorical selection or substitution, with the following prototypically Beckettian utterance of an aphasic patient: "But I am here bellow, well if I have been I know not, who that, now if I, if that now but, still, yes. What you here, if I, oh I know not, who that here was yes." "Thus only the framework," Jakobson continues, "the connecting links of communication, is spared by this type of aphasia at its critical stage." In another example cited from Fritz Lotmar, upon being shown the picture of a "compass," the patient experiences the tip-of-the-tongue phenomenon. When asked to name the pictorial sign of the "compass," he replies: "Yes, it's a ... I know what it belongs to, but I cannot recall the technical expression ... Yes ... direction ... to show direction ... a magnet points to the north."

2 I am using the revised Oxford translation of Aristotle's Complete Works (Aristotle, The Complete Works of Aristotle, ed. Jonathan Barnes, Princeton University Press, Princeton, NJ 1995).

3 Roman Jakobson, On Language, Harvard University Press, Cambridge, Massachusetts 1990.

4 With reference to Jakobson's analysis of the twofold character of language, Lacan's formula of metonymy emphasizes this resistance of signification, where the signifying function $(f S)$ of the linking of the signifier to the signifier (S...S') is congruent with () the maintenance of the bar (-) that separates the signifier from the signified so that no new meaning (s) can be produced: $f\left(\mathrm{~S} . . . \mathrm{S}^{\prime}\right) \mathrm{S} \cong \mathrm{S}(-)$ s. See Jacques Lacan, Écrits, W.W. Norton \& Co., New York 2006, pp. 428-429.

5 Jakobson, On Language, p. 122.

6 Ibid., p. 123. 
The prime example of this uncanny proximity between the similarity disorder, as conceived of by Jakobson, and universal olfactory anomia, as proposed here, is provided by the famous case of H.M. In 1953, in an attempt at surgically alleviating his severe epileptic seizures, Henry Molaison, sometimes considered neuropsychology's most famous patient, underwent a bilateral temporal lobe resection that resulted in anterograde amnesia, a nearly complete loss of the capacity to form new memories. ${ }^{7}$ In 1983, a study of H.M.'s olfactory capacities yielded equally salient results. ${ }^{8}$ H.M. exhibited an olfactory impairment that related neither to detection, nor to adaptation and intensity discrimination, but rather exclusively to recognizing and naming the qualities of his olfactory perceptions. A brief glance at the results of testing H.M.'s ability to name common odorants reveals that, in attempting to name them, he is displaying standard symptoms of similarity disorder. Much like Lotmar's patient who, unable to identify the presented object as "compass," names the object metonymically by using descriptors such as "direction" and "a magnet points to the north," instead of qualifying the presented odorant as "cloves," "mint," "raspberry," or "rose," H.M. would qualify them as "Dead fish, washed ashore," "An acid," "Carrion, a squirrel," and "Bad water," respectively. Does that which we call "rose" by the words "bad water" smell as sweet?

NAMING OF COMMON ODORANTS BY H.M. ${ }^{9}$

Odour

Coconut

Mint

Almond

Lemon

Vanilla

Orange

Cloves
Test 1

'Soap'

'Flowers'

'A wild flower'

'Flowers'

'Weak roses'

'An acid'

'Fresh woodwork'
Test 2

'Flowers'

'An acid'

'An acid'

'An acid'

'Newly made paper'

'Weak perfume'

'Dead fish, washed ashore'

7 The abundance of articles, published in major American newspapers, remembering this "unforgettable amnesiac" (as The New York Times described him) only days after his death in 2008, give us a good sense of H.M.'s notoriety. Unless lending their name to a disorder, a patient's fame very rarely exceeds that of those who treat them.

8 See H. Eichenbaum, T. H. Morton, H. Potter, \& S. Corkin, "Selective Olfactory Deficits in Case H. M.”, Brain: a Yournal of Neurology 106 (2/1983), pp. 459-72.

9 Ibid., p. 467. 


$\begin{array}{ccc}\text { Raspberry } & \text { 'Flowers' } & \text { 'Carrion, a squirrel' } \\ \text { Rose } & \text { 'A rose flower' } & \text { 'Bad water' } \\ \text { Water } & \text { 'I can't smell anything' } & \text { 'I can't smell anything' }\end{array}$

To be clear: what concerns us here, is not H.M.'s anomia, but our own. The point is not merely that H.M. exhibits a similarity disorder that would result from brain damage that he suffered; the point is rather that our own normal ability of naming smells already qualifies as a universal similarity disorder. This becomes clear the moment we cease focusing on columns 2 and 3 (Test 1 and Test 2), instead looking at the "veridical labels" indicated in column 1 (Odour) and listing the generic names of odorant objects that H.M. is unable to retrieve and convey. These labels testify to the fact that when it comes to naming odors all of us are aphasics, unable to name the qualities of smells, instead having to rely on metonymical stand-ins in form of names of the odors' most representative referents ("coconut," "mint," etc.). Paradoxically, all generic names for smells are non-generic and hence specific; moreover, they are specific to something other than smells.

The universal olfactory anomia is further redoubled by a partial olfactory agnosia that, in effecting an inability of source-naming familiar smells, further mirrors H.M.'s condition. As it turns out, the antinomy of names and smells, seemingly resolved by source-naming ("smell of rose"), step-naming ("sweet smell") or a combination of the two ("sweet smell of rose"), in fact stubbornly persists as a pronounced and striking human inability of odor-identification. Experiments suggest that although

humans detect odors quite well and can discriminate between hundreds of odors, their ability to identify an odor is extremely limited. In an unaided identification task, a person with a normal sense of smell is seldom able to identify familiar odors in $>50 \%$ of the cases ... One recognizes an odor as familiar and belonging to a general category, but is unable to recall its specific name. When given the name of the odor, it is recognized immediately and one is puzzled why one could not retrieve it before. ${ }^{10}$

10 Claire Sulmont-Rossé, Sylvie Issanchou and E. P. Köster, “Odor Naming Methodology: Correct Identification with Multiple-choice versus Repeatable Identification in a Free Task", Chemical Senses 30 (1/2005), p. 23. 
Even with source-names and step-names readily available and at hand, half the time we are still unable to retrieve and relate them to everyday olfactory impressions. Our immediate physical ability of detecting and interpreting olfactory sensations is unimpaired-we are anomic, not anosmic. We are able to detect smells, i.e. their presence or absence; distinguish between their intensities, i.e. discriminate, in Kantian terms, between "stronger" or "weaker" realities of smells as they affect our sense; and "recognize [them] immediately" as qualities. However, we are curiously unable to recognize and name the objects that emit them and that provide them with their common names. But unlike normosmic subjects, who-once the odor name was given to them-could "recognize [it] immediately,” H.M.'s “performance was not improved when odour names were given ... Once, having correctly identified a lemon by sight, he sniffed it and remarked, 'Funny, it doesn't smell like a lemon!'”11 Consider in this regard the following example of an aphasic patient with a similarity disorder who, when asked to simply repeat back a word, cannot bring himself to do it: "Told to repeat the word no, Head's patient replied 'No, I don't know how to do it.' ... he could not produce the purest form of equational predication, the tautology $a$ $=a: / n o /$ is $/ n o / .{ }^{\prime 12}$

\section{Funny, It Doesn't Smell Like a Lemon}

A chimeric encounter: a lemon that doesn't smell like a lemon; a word that can't be substituted for itself. Incapable of calling odors presented to him by their correct names, H.M. is also unable to distinguish between them, their differences steadily collapsing into indifference: coconut and mint, lemon and raspberry are all equated with "flower"; mint, almond, lemon and orange all smell like "an acid." But while he erratically discovers precarious identities where there are only differences, he also discerns difference where there is only identity: vanilla, for instance, is made to differ from itself by equaling both "weak roses" and "newly made paper." In none of the individual cases are the two smellnames H.M. provides in linguistic agreement, nor are they in agreement with the smells' veridical labels or their generic names. ${ }^{13}$ Each time H.M. catches a whiff of something, this something is subjected to incessant and repetitive "self-oth-

\footnotetext{
Eichenbaum et al., "Selective Olfactory Deficits in Case H. M.”, p. 469. Jakobson, On Language, p. 123.

${ }_{13}$ That is, in none of the cases except for one: water, which is characteristically odorless.
} 
ering," Sichanderswerden, to use Hegel's term. If he is unable to identify identical odors as same, and different odors as different, it is precisely because a smell, standing for the nameless void of naming, is never identical with itself. The defect in substitution, characteristic of the similarity disorder generally and of the universal olfactory anomia specifically, hence does not merely affect the subject's ability of substituting one name for another, but encompasses substitution at its purest, that is, the substitution of a name for itself.

The impossibility of directly naming olfactory impressions as sensuous qualities of objects therefore extends beyond their perceptual emergence in the relation between a perceiving subject and the object of their perception so as to encompass an inability of naming these objects themselves. When no assistance is required in conjuring up a source-name with which to identify a given smell, the "veridical label" or "correct odor name" given and related to an olfactory impression still remains intrinsically unstable and precarious. Hence, we should pause here to reflect on the term "veridical label" itself. The later defines a "correct" smell-name as the one considered to coincide with the reality of its respective odorant. The veridical labels are hence taken to correspond to the reality of the odorant-object they name. Such correspondence lies at the core of the traditional philosophical notion of truth as adequatio or correspondence between knowledge and being, intellect and thing, or proposition and reality. Here, we clearly perceive the centrality of the problem of naming to classical ontology as it depends on the notion of names as latching onto things in their essential being.

Since the beginnings of Western philosophy, the problems of truth and naming were considered principally interdependent. And Plato-in his Cratylus, explicitly concerned with "correctness of names"-was in fact the first to systematically broach the issue of "veridical labels." Since the concept of truth as adequatio ultimately hinges on the relation of reflexive identity $(\mathrm{A}=\mathrm{A})$, the correct name is not simply the one that succeeds in latching onto the thing, but the one that succeeds in adequately (truthfully) designating the object in its identity with itself, thus revealing its nominata's essential being. Ultimately, it is such use of names that distinguishes philosophical discourse from that of the sophist, who at best is concerned with "correct diction," orthoepeia, disregarding the correctness of names, orthotes onomaton. As we have seen, H.M.'s anomia, taken here as revealing of the very essence of smells, radically subverts the relation of equality by undermining its reflexivity, i.e., it subverts the principle that things 
"are by themselves, in relation to their own being or essence, which is theirs by nature." (Crat. 386e) ${ }^{14}$ Names, according to Plato, are imitations of things in their essential being, their truthful copies; however, the moment the copies lose their grip on their models or things, things themselves seem to run amok, losing their essential being.

Names are seen as latching onto self-identical objects, however, by Plato's lights, they do so in a way that is itself revealing of the self-identical essence. Signifiers are taken to be meaningful in themselves, they inhabit the true sense of what they express. They are in possession of meaning, or-better still-are entirely possessed by it. And for Plato, this true sense is revealed by etymological examination, itself etymologically revealing of its own essence as logía, "study of," étumon, "true sense.” To pick only one example out of the myriad etymologies proposed by Plato, that of anthrōpoi, "humans": "The name "human' signifies that the other animals do not investigate or reason about anything they see, nor do they observe anything closely. But a human being, no sooner sees something-that is to say, 'opoppe'-than he observes it closely and reasons about it. Hence human beings alone among the animals are correctly named 'anthrōpos'-one who observes closely what he has seen (anathrōn ha opope)." (Crat. 399c) The true sense of "human" is revelatory of a capacity essential to humans, which makes "human" a correct name. Not do dwell on the dubiousness of Plato's etymological endeavors, it is nevertheless important to note that his attempts are entirely oriented by meaning which-with great virtuosity and substantial efforts-is made to fit the names, bringing metonymic deferral to a standstill. Plato's etymologies are an exorcism in reverse; their function is to charge signifiers with meaning so as to reveal how meaning always-already takes charge of them. If one makes the effort to "observe closely what one has seen," the name will reveal itself as what it is: an anagram of the thing. Accordingly, every correct name is in fact a source-name and all names are eponymous, i.e., named after the essential being of the things they name. ${ }^{15}$

${ }_{14}$ I am using Plato's Complete Works (Plato, Complete Works, ed. John M. Cooper, Hackett Publishing Company, Indianapolis 1997).

15 One has to wonder what Platonic etymologies would say about the names of Plato's teachers. Do the names Cratyus and Socrates reflect the same essential being, possibly reducible to kratos, "power" or "strength"? And is "Plato" the name of the "distance" or "width" (from platús, "broad, wide") that spans between the two-their interface? 
Words have a hard time latching onto smells in their essential being. In the smellscape, nothing smells like itself because nothing is itself. The first way to approach this claim would be the following one: We only ever smell that which is already wasting away, caught in the process of self-dissipation, inhabiting the edge of being. In his discussion of the physical senses, Hegel singles out this crucial aspect of smell in very precise terms: "Denn zu riechen ist nur dasjenige, was schon in Sichverzehren begriffen ist," "For we can smell only what is in the process of wasting away." 16 "Wasting away," though, might not be the best translation for Hegel's Sichverzehren. The two terms can even be considered opposites: if we abstract from their reflected senses and consider their immediate linguistic meaning, "wasting away" implies a lack, particularly a lack of nourishment required to sustain me, thereby signifying a process of weakening and of a gradual loss of strength. Sichverzehren, on the other hand, signifies the surplus-process of being devoured, ravenously eaten up, avidly enjoyed to the point of destruction. Think of Kafka's "hunger artist": his aesthetic practice exceeds mere fasting. A hunger artist is not simply a hungering artist wasting away. Instead of not eating, of abstaining from food, the hunger artist emphatically eats nothing-hunger is his nourishment. Perhaps a keen sense of smell is required to fully grasp this point, for another of Kafka's protagonists, a dog, would say it best: to truly comprehend the notion of nourishment, one needs to sink one's teeth into hunger. Furthermore, Sichverzerhren is also a self-devouring, enacted not by an external agent but by the very substance undergoing its own dissolution. It indicates, for lack of a better word, an epithanatotic process of self-dissolution, which in turn is the dissolution of the self, of one's own reflexive identity. ${ }^{17}$ Adorno and Horkheimer emphasize the aspect of self-devouring as

16 G.W.F. Hegel, Vorlesungen über die Ästhetik I, in Werke, Vol. 13, Fischer Verlag, Frankfurt am Main 1970, p. 184; Aesthetics: Lectures on Fine Art, Clarendon Press, Oxford 1975, p. 138. A more detailed analysis of this passage can be found in Simon Hajdini, Kaj je ta duh? K filozofiji voha, Analecta, Ljubljana 2016.

${ }_{17}$ If the sense of smell is the lousiest of identifiers, we might be surprised to learn that it is an astoundingly accurate predictor of impeding death. Scientists from the University of Chicago have shown that as an indicator of death in the next five years anosmia, i.e. the loss of the sense of smell, only comes second to severe liver damage (see Jayant M. Pinto et al., "Olfactory Dysfunction Predicts 5-Year Mortality in Older Adults”, PLoS ONE 9 (10/2014). Recently, empirical studies revealed that the loss of smell is also the best predictor and indicator of COVID-19 infections (https://news.harvard.edu/gazette/story/2020/06/ app-reveals-loss-of-taste-smell-coronavirus-indicators/). Smell and the death drive-I will return to this elsewhere. 
a devouring of the self in their famous line from the Dialectic of Enlightenment: "Im Sehen bleibt man, wer man ist, im Riechen geht man auf," "When we see we remain who we are, when we smell we are absorbed entirely." ${ }^{18}$ The moment I smell, my self-identical Self comes undone, dissipating, ceasing to be itself. ${ }^{19}$

It is no surprise that Cratylus of Athens, Plato's teacher, should have felicitously captured the self-othering dissolution of reflexive identity by reproaching his own teacher, Heraclitus, "for saying that it is impossible to step twice into the same river; for he thought one could not do it even once." (Met. 1010a10) H.M.'s olfactory anomia recapitulates the gist of Cratylus's hypercritique of Heraclitus. For H.M., it is not only impossible to catch a whiff of the same smell twice, the later having already been transformed in the process; he cannot do it even once. Hence, the partial olfactory agnosia, as considered here, is not a cognitive disorder that would result from brain damage (as it is typically assumed to be the case), but rather stands for the "brain damage" of cognition itself, that is, for the inherent deadlock of the cognitive process. And while anomia typically stands for a form of aphasic disturbance that is considered a pathological deviation from the subject's normal ability to use language, the universal olfactory anomia points not to a pathological deviation from the norm but rather to an intrinsic pathology of the norm itself: as permeated with lexical voids, language is deodorized.

\section{Rose is a Rose is a Rose is a Rose}

Aristotle famously defines the category of quality as an abstract property pertaining to concrete things. In conceptualizing the relation between quality and

18 Max Horkheimer and Theodor W. Adorno, Dialektik der Aufklärung. Philosophische Fragmente, Fischer Verlag, Frankfurt am Main 2006, p. 193; Dialectic of Enlightenment. Philosophical Fragments, Stanford University Press, Stanford, CA 2007, p. 151.

19 The "self-devouring" nature of smell (in both senses of the term), as well as its antinomic relationship to language, is bound to make us think of the alternative so dear to Deleuze: "to eat or to speak," either "bits of things" or "bits of Shakespeare”. Gilles Deleuze, The Logic of Sense, Columbia University Press, Columbia, NY 1990, p. 23. With the emergence of speech, the mouth is deterritorialized, stripped of its natural function and robbed of its natural object, so that to speak is to hunger. See Gilles Deleuze and Félix Guattari, Kafka. Pour une littérature mineure, Minuit, Paris 1975, p. 35. As we have seen, smell complicates this schema. Can the nose be deterritorialized? Or does it stand for an irreducible territoriality, immune to linguistic deterritorialization of sensibility? 
the qualified, Aristotle also considers the problem of naming: the concrete thing qualified is named after, or in relation to, its abstract quality, or: qualifieds are paronyms of qualities (Cat. 10a 27-30). This is true, Aristotle continues, "in practically all" cases, meaning that "in most cases ... things are called paronymously, as the pale man from paleness." There are exceptions to this observation, however, which Aristotle pauses to consider. First, there are qualifieds, such as "boxer," the names of which are not paronymously derived from any quality that would signify the "skill of boxing," "for there are no names for the capacities in virtue of which these men are said to be qualified" (Cat. 10a 32 - 10b 6). However, even though the names of such qualifieds are not derived paronymously from the names of qualities in virtue of which they are qualified, their names are nevertheless paronymously derived from another identifiable name (say, from "boxing"). In other cases, which are equally rare, the quality itself has a name, but the paronym of the qualified is derived from a name other than that of the quality of which it is the qualified (Cat. 10b 6-10).

Let us now consider this logic from the perspective of the problem of naming and smells. In the case of step-naming, the name of the qualified ("sweet") is a paronym of a quality ("sweetness"), however, as such it is not derived from the name of a quality in virtue of which it is qualified (for such a quality has no name) and is thus a paronym of an essentially non-olfactory quality pertaining to gustatory sensation which is used to the effect of relating an olfactory quality to an olfactorily qualified thing in the absence of the quality's proper name. In the case of source-naming, the relation of derivation is not merely translated into another sensory register and thus kept intact. Here, the name of the qualified ("smell-of-rose" or "rosy") is derived from the name of the quality ("smellof-rose-ness" or "rosiness"), which refers to the name of the odorant ("rose"), which derives from the name of the object ("a rose") that is said to be representative of the missing quality (the un-named "X"). But derivations such as these ("rose," "rosy" and "rosiness," or "mint," "minty" and "mintiness," etc.) are deployed rarely and perhaps for the sole purpose of linguistically marking the conceptual difference between what are in fact not three but four interrelated terms. Commonly, we would use a single word ("rose") for an empirical object ("a rose"), an odorant ("rose"), an olfactory quality ("rose") and its qualified ("rose"): Rose is a rose is a rose is a rose... 
In olfactory source-naming, the name of the qualified (a thing "smelling of rose") is a paronym not of a quality ("X") but of an object ("a rose") standing in for the lacking quality (now called "rose"). ${ }^{20}$ Unlike with other sensuous qualities, such as that of "whiteness" that can be related to its qualified ("white") without a reference to a particular referent (say, "snow"), olfactory qualities ("rose") are linguistically undistinguished from the names of their corresponding qualifieds ("rose"), as well as linguistically undistinguishable from their odorant ("rose") or referent ("a rose"). The one crucial consequence of this un-distinguishability that tends to hide in plain sight is that the moment we pose the problem of naming and smells we find ourselves caught in a loop of classification, where a given quality is the common attribute of a certain number of objects, which include among them this quality itself. It is as if a set of objects qualified as "white" would include the quality of "whiteness" as one of its qualified objects. Unlike the smell we call "rose" that qualifies objects, including "a rose," as smelling of "rose," "whiteness" qualifies objects ("snow," "milk," etc.) as "white," but is itself not an object qualified by itself as "white." The olfactory quality we call "rose" is that in virtue of which, apart from a number of other objects ("soap," for instance), "a rose" is qualified as "smelling of rose," that is, as smelling of itself. There is one such self-referentially qualified referent for every olfactory quality expressed by source-naming, which implies that any particular olfactory set of qualified members is a set that includes itself as its member. Or put differently: for any set of objects qualified in virtue of a given olfactory quality there is One that qualifies all other objects-and itself.

Another way of capturing this loop of classification is provided by the generaspecies distinction introduced by Aristotle so as to spell out a key difference between qualities and their qualifieds. Whereas qualities as genera "are spoken of in relation to something, ... none of the particular cases [or qualifieds] is" (Cat. 11a 20-25). Aristotle takes "knowledge" to be the example of a genus; as such, the quality of "knowledge" is always spoken of in relation to something, while its species, for instance "grammar," is not. Genera or qualities are relatives, species or qualifieds are not. Species only enter the relative-form as

20 "Whiteness" is a quality of an object qualified as "white." But the qualified is not to be equated with the object: "whiteness" is that in virtue of which, for instance, "snow" (as an object) is qualified as "white," meaning that the quality of "whiteness" does not correspond to the object "snow" but rather to the color "white" as its qualified. 
species of their genera: "grammar" is not "grammar of something," but rather "knowledge of something." Or, take the example of the quality of color. Color is a genus and hence is spoken of in relation to something: we speak of the "whiteness of snow" but not of "snow of something." And just like "grammar" is a particular species of the genus "knowledge" and hence the "knowledge of something," "snow" is a particular qualified species of the genus "whiteness" and hence stands for the "whiteness of something." Now, Aristotle goes on to add, "there is nothing absurd" about a thing being both a qualification and a relative (Cat. 11a 35); for instance, "music" is a form of "knowledge" and hence a "knowledge of music," but "music" can also be spoken of in relation to something like, say, the "film" ("film music"). The moment we consider our particular example of smell, an instance of redoubling becomes obvious: "“smell of rose' of a rose." "A rose" as a particular case of the genus "smell of rose" is in fact spoken of in relation to something, but unlike "music" it is not simply spoken of in relation to something other than itself ("film") but in relation to itself. The genus is spoken of in relation to its species which, generally, are not themselves spoken of in relation to anything; however, for each genus of smell, there is one species (in relation to which the genus is spoken of) that is itself spoken of in relation to the genus, i.e. to itself.

The biblical story of the formation of Adam is a story of the making of "man" and of "mankind" (with the two referred to indiscriminately as "the man") and hence the perhaps ultimate example of the redoubling that is at stake here. It is only from the moment when Eve is formed from Adam's rib (and formed as a "woman") that the name "Adam" begins to signify both the species of "man" and the genus of "man(kind)." "Man" (as in "male human") can only enter into a relation of distinctive opposition with "woman" (as his "female" counterpart) on condition of entering into an opposition with himself as "man(kind)." The genus and species of "man" emerge at the same point in logical time, in the immediate aftermath of the emergence of the "woman." In the story, this redoubling, or splitting, whereby the genus "man" as standing for "mankind" appears as one of its own species ("male human") and therefore as different not merely from its other ("woman") but also from itself, coincides precisely with the introduction of the lack: "Woman" is made out of "man's" rib, literally standing in for what "man" henceforth is lacking. 
It is interesting to note that Eve comes into being-triggering this self-split of "man"-as an immediate consequence of Adam's encounter with a void of naming: God was looking to make "a helper fit for him," for it "is not good that the man should be alone," so he "formed every beast of the field and every bird of the heavens" and "brought them to the man to see what he would call them. And whatever the man called every living creature, that was its name." (Gen. 2: 18-23) The making of the "helpers" is God's work, the making sense of them is the work of man. But the moment Adam made sense of the "helpers" by calling them by their names, he realized that he has "not found a helper fit for him," meaning that among all these names he had just uttered one name was missing. And as a good Freudian, God looked for the missing name in Adam's "deep sleep": "So the LORD God caused a deep sleep to fall upon the man, and while he slept took one of his ribs and closed up its place with flesh. And the rib that the LORD God had taken from the man he made into a woman and brought her to the man." The man exclaimed: "This at last is bone of my bones / and flesh of my flesh; / she shall be called Woman, / because she was taken out of Man." Thus, "woman" quite literally emerges from "man's" lack. As a stand-in for the missing name, she emerges from a void of naming. But the emergence of "woman" in the place of the lacking name does not result in the totalization of the universe of names, henceforth neatly ordered and complete. Rather, with this name ("woman") "man" himself is split into two, with a part of him appearing outside of himself ("she was taken out of Man"). For this reason, "woman" is not merely a symmetrical opposite of "man" but rather (as Lacan claims) his symptom, that is, the symptom of "man's" thwarted relation to himself as "man," just as smell is the generic symptom of naming's thwarted relation to itself. Take again the genus of "whiteness" and, for instance, the difference between two qualified species of "snow" and "milk." The difference between the two is the difference between two species as species of the genus "whiteness." However, with "a rose" and, for instance, "soap" (as qualified by the same quality of "smell of rose"), or between "man" and "woman," the difference between the two species ("rose" and "soap," "man" and "woman") coincides with a difference between a species ("soap," "woman”) and its genus ("rose," “man[kind]”).

An olfactory source-name simultaneously stands for an "ordinary" quality qualifying its qualifieds ("soap" smells of "rose") and for an "empty" quality qualifying itself ("a rose" smells of "rose" which smells of "a rose"). An olfactory quality qualifies not only something other than itself but also itself as an 
other. In marking sensuous objects with a distinctive qualitative difference, it simultaneously marks itself as split and as differing from itself-the point being that with each source-name the externality of the nameless void of naming that characterizes the realm of smells is not simply named, linguistically integrated, contained and aborted but is rather transposed and emerges as the inner heterogeneous void splitting source-names from within. Apart from being an ordinary name for a number of qualifieds, every source-name is an empty name for itself, and as such it is the name of the lack of itself as a name, the name of the un-named " $X$ " standing for the void of naming. As an empty instance of tautological self-reflexivity that lacks grounding in the missing name, a sourcename stands in the relation of reflexive opposition ${ }^{21}$ to itself. Recall, once more, the case of H.M. His deficit only pertained to the olfactory mode, meaning that he was able to name the objects by sight or touch, but not by smell. On one occasion, after identifying a lemon by sight, "he sniffed it and remarked, 'Funny, it doesn't smell like a lemon!”"22 H.M.'s remark about the "lemon” not smelling like a "lemon" points precisely to the aforementioned inner gap of reflexivity: the self-identity of an object, i.e. its reflexive identity, is thwarted by the relation of reflexive opposition, that is, by a difference or negativity separating the entity from itself. In paraphrasing Lacan's definition of the signifier as that which represents the subject for another signifier, we can say that a source-name represents the subject of smell for another (lacking, un-named) name.

We began the essay with the maximum opposition, in fact an antinomycal relation between names and smells. But the discussion of source-names that are commonly used as lexical stand-ins for the missing proper names has-perhaps and perhaps surprisingly-lead us to affirm the equivalence of names and smells. Is not every proper name ultimately an empty name, a "rigid designator" 23 of an object irreducible to the cluster of its positive descriptive properties, in turn

${ }^{21}$ I propose the term "reflexive opposition" to signify the property of reflexivity as central to Lacan's notion of the relation of opposition. This centrality was clearly articulated by Jean-Claude Milner in Le périple structural as the basic tenet of what he terms Lacan's "hyperstructuralism". Jean-Claude Milner, Le périple structural, Éditions du Seuil, Paris 2002. I am thankful and indebted to Jean-Claude Milner for his patience in discussing the concept with me in our private communications.

22 Eichenbaum et al., "Selective Olfactory Deficits in Case H. M.”, p. 469.

23 See Saul Kripke, Naming and Necessity, Harvard University Press, Harvard, Massachusetts 1980. 
designating the un-named property " $\mathrm{X}$ "? Or is there a difference between the two, one that ultimately makes them irreducible? A proper name, say "Peter," stands for a number of descriptive properties of its referent; but contrary to the central claim of the Frege-Russell description theory of names, these properties are never exhaustive and are only exhausted in the name that covers all of these properties, including the empty excess of singularity that they themselves do not and cannot exhaust. However, in light of our discussion of smells and naming, another crucial element has to be added to the philosophical notion of the proper name. The mysterious property "X," designated by the name "Peter" and un-namable in terms of the descriptive properties that determine "Peter's" biographical identity, can be "rigidly designated" by the name "Peter" only because this name is itself a stand-in for a lacking name. There are many Peters, Peter differs from Peter and Peter from Peter, but not in name and not only in respect to his positive descriptive properties. "Peter" is singular and distinctive (from any other "Peter") not because of the properties he has, and not because of the properties he lacks, but because of the property he has lacking ("X"). A proper name like "Peter" is a taking possession, a rigid nominal containment of the property lacking the name.

To conclude, let us take a look at the parental ritual of picking the newborn's name which testifies to this logic. When picking the child's name, we are not merely assessing the qualities of available names while considering their personal (familial) or social meaning as it relates to factors of custom, religion, political ideology, class, ethnicity, education, etc. In addition to relating them to identifiable meanings, we are also relating these sonorous and literal qualities to our (unborn) child's supposed singularity, to his or her un-named "X," and determining which name best fits that which is ultimately meaningless. In short: we are effectively searching for a name that would be the best stand-in for the missing proper name, that is, for a name that could, would it not be lost, directly name and thus fit the quality "X."

The parent's occasional obsession with what we (as mere observers) mockingly refer to as "made up names," is symptomatic of this process: such neonyms are attempts to by-pass the by-pass, that is, to by-pass the choice inherent in the process of naming, to find a way around the available stand-ins and to directly conjure up the lacking name that would fit the quality " $\mathrm{X}$ " without a remainder. (Without a remainder-or should we say without the spectral, surplus flesh from 
the biblical story that emerges in the place of the lack, never quite filling and befitting it?) What these parents in their quest for a unique linguistic expression of the singular object tend to overlook is the fact that the available fond of names already consists of nothing but such attempts at directly naming the un-named, that is, they overlook the fact that the history of names is itself already an historical archive of structurally failed attempts of naming the singular. In addition to this, the parental attempts of directly naming the " $\mathrm{X}$ " usually backfire (at least for us as observers) in effecting the opposite of what was intended. They often amount not to a fortuitous complete overlapping of Being and Sense, but rather to a metamorphosis of the supposed sublime singularity of the precious object into an obscene linguistic parody of a ridiculous abject. What gets lost in this operation of directly determining or localizing the undetermined and impossible element " $\mathrm{X}$," is precisely the " $\mathrm{X}$ " itself that only persists in the by-pass, that is, in and through our failures of naming it.

\section{References}

Aristotle, The Complete Works of Aristotle, ed. Jonathan Barnes, Princeton University Press, Princeton 1995

Deleuze, Gilles, The Logic of Sense, Columbia University Press, Columbia, New York 1990 Deleuze, Gilles, and Félix Guattari, Kafka. Pour une littérature mineure, Minuit, Paris 1975 Eichenbaum, H., T. H. Morton, H. Potter, \& S. Corkin, "Selective Olfactory Deficits in Case

H. M.”, Brain: a Yournal of Neurology 106 (2/1983), pp. 459-472

Hajdini, Simon, Kaj je ta duh? K filozofiji voha, Analecta, DTP, Ljubljana 2016

Hegel, G. W. F., Vorlesungen über die ÄsthetikI, in Werke, Vol. 13, Fischer Verlag, Frankfurt am Main 1970

- Aesthetics: Lectures on Fine Art, Clarendon Press, Oxford 1975

Horkheimer, Max, and Theodor W. Adorno, Dialektik der Aufklärung. Philosophische Fragmente, Fischer Verlag, Frankfurt am Main 2006

- Dialectic of Enlightenment. Philosophical Fragments, Stanford University Press, Stanford, CA 2007

Jakobson, Roman, On Language, Harvard University Press, Cambridge, Massachusetts 1990

Kripke, Saul, Naming and Necessity, Harvard University Press, Harvard, Massachusetts 1980

Lacan, Jacques, Écrits, W.W. Norton \&Co., New York 2006

Milner, Jean-Claude, Le périple structural, Éditions du Seuil, Paris 2002 
Pinto, Jayant M., et al., “Olfactory Dysfunction Predicts 5-Year Mortality in Older Adults”, PLOS ONE 9 (10/2014)

Plato, Complete Works, ed. John M. Cooper, Hackett Publishing Company, Indianapolis 1997

Sulmont-Rossé, Claire, Sylvie Issanchou, \& E. P. Köster, “Odor Naming Methodology: Correct Identification with Multiple-choice versus Repeatable Identification in a Free Task,” Chemical Senses 30 (1/2005), pp. 23-27 